\title{
SINKRONISASI DATA DENGAN PEMROSESAN PARALEL MENGGUNAKAN MODEL PEMROGRAMAN MAPREDUCE
}

\author{
Murti Retnowo \\ Jurusan Manajemen Informatika, UTY, Yogyakarta \\ e-mail: nowo.yogya@gmail.com
}

\begin{abstract}
ABSTRAK
Penelitian dalam pemrosesan data menunjukan bahwa semakin besar data semakun membutuhkan waktu yang lebih lama. Pemrosesan data berukuran besar pada komputer tunggal memiliki keterbatasan yang dapat diatasi dengan memproses data secara paralel. Penelitian ini memanfaatkan model pemrograman MapReduce pada sinkronisasi data dengan melakukan duplikasi data dari database client ke database server. MapReduce adalah model pemrograman yang dikembangkan untuk mempercepat pemrosesan data berukuran besar. Penerapan model MapReduce pada proses pelatihan dilakukan pada pembagian data yang disesuaikan dengan jumlah sub-proses (thread) dan pemasukan data ke database server serta menampilkan data hasil sinkronisasi data. Percobaan dilakukan dengan menggunakan data sebesar 1.000, 10.000, 100.000 dan 1.000.000 data, serta menggunakan thread sebanyak 1, 5, 10, 15, 20 dan 25 thread. Hasil penelitian menunjukan bahwa penggunaan model pemrograman MapReduce dapat menghasilkan waktu yang lebih cepat, namun waktu untuk membuat thread ketika jumlah thread yang banyak memerlukan waktu yang lebih lama. Hasil penggunaan model pemrograman MapReduce dapat memberikan efisiensi waktu dalam melakukan sinkronisasi data baik pada database tunggal maupun database terdistribusi.
\end{abstract}

Kata Kunci: mapreduce, sinkronisasi data, multithread, message passing, Static Tasks Assigment

\begin{abstract}
Research in the processing of the data shows that the larger data increasingly requires a longer time. Processing huge amounts of data on a single computer has limitations that can be overcome by parallel processing. This study utilized the MapReduce programming model data synchronization by duplicating the data from database client to database server. MapReduce is a programming model that was developed to speed up the processing of large data. MapReduce model application on the training process performed on data sharing that is adapted to number of sub-process (thread) and data entry to database server and displays data from data synchronization. The experiments were performed using data of 1,000, 10,000, 100,000 and 1,000,000 of data, and use the thread as much as 1, 5, 10, 15, 20 and 25 threads. The results showed that the use of MapReduce programming model can result in a faster time, but time to create many thread that many require a longer time. The results of the use of MapReduce programming model can provide time efficiency in synchronizing data both on a single database or a distributed database
\end{abstract}

Keywords: data synchronization, mapreduce, message passing interface multithread, static tasks assigment

\section{PENDAHULUAN}

$\mathrm{K}$ ebutuhan akan kemampuan komputasi yang besar pada saat ini untuk melakukan pemrosesan data dalam skala besar dan waktu yang singkat menjadi hal yang sangat mendasar guna memaksimalkan kerja dan mencapai tujuan yang akan dicapai dalam perusahaan. Beberapa bidang yang membutuhkan komputasi tingkat tinggi adalah simulasi, perhitungan dan pemrosesan data. Masalah-masalah tersebut sering kali membutuhkan kalkulasi repetitif pada sejumlah data yang besar untuk memperoleh hasil yang valid. Selain itu sistem komputasi harus dapat menyelesaikan masalah dalam waktu yang masuk akal.

Komputasi tradisional yang memiliki prosesor tunggal untuk melaksanakan tugas-tugas dari suatu program merupakan salah satu cara untuk meningkatkan kinerja dalam melakukan pemrosesan data. Akan tetapi dengan prosesor tunggal masih memerlukan waktu yang lama, hal ini disebabkan karena komputer akan mengambil data satu per satu dari masing-masing server data yang berada pada lokasi yang berbeda-beda. Pada kenyataannya perusahaan sering kali menuntut agar simulasi, perhitungan dan pemrosesan data dapat diselesaikan dalam hitungan menit bahkan detik. Simulasi yang diselesaikan dalam hitungan hari biasanya tidak dapat diterima. Waktu yang diperlukan untuk melakukan simulasi, perhitungan dan pemrosesan data haruslah sesingkat mungkin agar informasi dapat diterima dalam waktu yang singkat dan akurat. Ada beberapa masalah yang memiliki tenggang waktu lama dalam pemrosesan komputasinya. Sebagai contohnya adalah pemrosesan data dalam jumlah yang besar dimana server data terletak pada beberapa komputer yang berbeda sehingga program memerlukan waktu yang lama untuk melakukan proses sinkronisasi atau penggabungan data dari masing-masing komputer [1].

Berdasarkan latar belakang masalah yang telah diuraikan diatas maka rumusan masalah pada penelitian ini adalah: melakukan proses sinkronisasi data guna memberikan informasi yang cepat dan akurat dengan memanfaatkan komputer yang sudah ada pada masing-masing server data dengan menggunakan model pemrograman mapreduce. 
Permasalahan yang akan dibahas pada penelitian ini memiliki ruang lingkup yang cukup luas, sehingga permasalahannya dibatasi sebagai berikut:

1) Proses MapReduce dilakukan pada jaringan lokal dengan spesifikasi komputer yang berbeda-beda (grid).

2) Komputer-komputer yang digunakan untuk membentuk grid atau sebagai node atau worker adalah beberapa komputer yang terhubung dalam suatu jaringan dan berada dalam satu switch (jaringan lokal).

3) Metode yang digunakan Message Passing Interface dan Static Task Assigment digabungkan dengan model pemrograman MapReduce.

Iqbal [2], melakukan penelitian tentang bagaimana menganalisis suatu Identitas unik yang dimiliki satu oleh setiap penduduk pada KTP agar tidak terjadi duplikasi KTP pada saat pembuatan, database yang disimpan berukuran Very Large Database maka membutuhkan sebuah Framework MapReduce dan suatu data warehouse agar dapat menganalisis Identitas penduduk yang disimpan pada database. Data di-export ke dalam format Text kemudian dilakukan proses pemetaan [3]. Kurniawan [4] melakukan penelitian untuk mencari anggota milis linux di Indonesia dengan MapRecude, dimana MapReduce difungsikan untuk melakukan pencarian terhadap data anggota, penambahan, penghapusan, melihat topic milis dan menjalankan data node pada sistem operasi berbasis linux[4].

\section{METODE}

Kebutuhan akan informasi yang cepat dan akurat menjadi hal yang penting pada saat ini. Informasi dibutuhkan oleh pihak manajemen untuk mengambil keputusan dalam proses produksi dan pembelian bahan baku periode berikutnya. Untuk mendapatkan informasi yang cepat dan akurat tentunya diperlukan komputer dengan spesifikasi hardware yang mendukung untuk pemrosesan data yang cepat dan tingkat kinerja yang tinggi dan program berbasis client-server dengan database yang terdistribusi dan dapat diakses dari semua komputer dalam sebuah jaringan lokal maupun jaringan publik merupakan salah satu cara meningkatkan efisiensi waktu dalam pengaksesan data.

Pergantian hardware komputer tentunya sangat membantu dalam menambah kecepatan pemrosesan data tetapi dengan pergantian hardware komputer memerlukan biaya yang banyak dan program yang selama ini sudah berjalan dengan baik belum tentu di support pada hardware komputer yang baru. Selain itu juga diperlukan perubahan setting dari komputer yang baru agar program dapat berjalan dengan baik.

Merubah program yang ada pada saat ini tentunya memerlukan waktu yang lama karena source code dari program yang berjalan tidak diketahui mana yang paling akhir dan bagaimana alur dari program yang berjalan, hal ini disebabkan karena programmer yang membuat program sudah pindah ditempat kerja yang baru. Membuat program yang baru tentunya memerlukan waktu yang lebih lama lagi karena programmer yang baru harus dapat memahami alur kerja dari program yang berjalan pada saat ini dan mengimplementasikannya pada program yang baru, memerlukan waktu lama untuk pembelajaran program baru bagi pengguna dan testing program untuk mengetahui kesalahan-kesalahan yang ada serta akan mengganggu proses kerja yang sudah berjalan dengan baik.

Selain masalah hardware komputer dan program yang berjalan adalah transaksi atau pemrosesan data yang dilakukan dibanyak lokasi dan database yang berbeda hal tersebut disebabkan program yang masih berjalan secara stand alone. Transaksi yang terjadi dibeberapa tempat yang berbeda dengan program yang masih berjalan secara stand alone tentunya akan mengakibatkan masalah tersendiri dalam melakukan proses sinkronisasi data walau sudah menggunakan database yang terdistribusi dalam hal ini menggunakan database MySQL, tetapi MySQL masih di-install pada masing-masing komputer dengan menggunakan setting user yang hanya dapat mengakses dari satu tempat saja (lokal komputer).

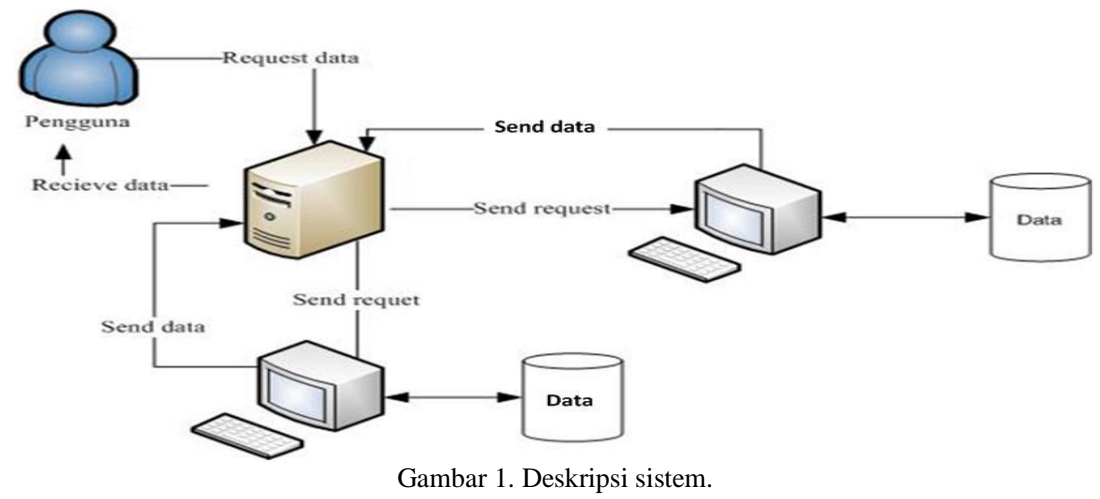

Salah satu tren yang sekarang ini digunakan pada perusahaan IT yang besar dalam menangani jumlah data yang besar dan terdistribusi adalah dengan model pemrograman MapReduce, dimana terdapat dua proses yaitu proses Map dimana data akan dibagi menjadi beberapa bagian sama besar dan proses Reduce dimana data akan digabungkan kembali dan dihilangkan jika ada data-data yang sama dari proses mapping sebelumnya. Proses 
MapReduce akan dijalankan dalam sebuah cluster atau grid yang terdiri atas beberapa komputer independent dengan melakukan proses secara simultan atau paralel (Multithread) yang digunakan untuk melakukan sikronisasi data, import data atau pencarian data pada database yang terdistribusi.

Model pemrograman MapReduce yang dipadukan dengan metode Message-Passing Interface (MPI) dan Static Tasks Assignment (STA) dan digunakan dalam bahasa pemrogramman Delphi selain diharapkan mampu meningkatkan kemampuan kinerja sistem dalam menangani data dalam ukuran yang besar dan terdistribusi juga mampu meningkatkan efisiensi dan efektivitas waktu kerja dalam melakukan proses sinkronisasi data dari banyak database client ke database server.

Deskripsi sistem secara garis besar dimulai dengan adanya proses permintaan data dari pengguna. Proses permintaan dan pengiriman data seperti ditunjukan pada Gambar 1 dimana ada pengguna melakukan permintaan data, permintaan data akan dikirimkan ke komputer server. Komputer server yang menerima permintaan data, secara otomatis akan mendistribusikan permintaan data ke masing-masing komputer client sampai disini komputer server sudah selesai melaksanakan pekerjaannya. Proses selanjutnya terjadi pada komputer client. Setelah menerima permintaan data selanjutnya komputer client akan mempersiapkan data yang diminta sesuai dengan kriteria yang sudah didapat dari komputer server, proses selanjutnya adalah melakukan mapping data atau mengumpulkan data yang akan dilakukan proses sinkronisasi ke database server secara paralel (multithread). Proses sinkronisasi data yang sudah selesai dilakukan akan dapat diakses oleh pengguna yang melakukan permintaan data tersebut sekaligus melakukan proses reduce atau menghilangkan data yang sama dengan kriteria tertentu.

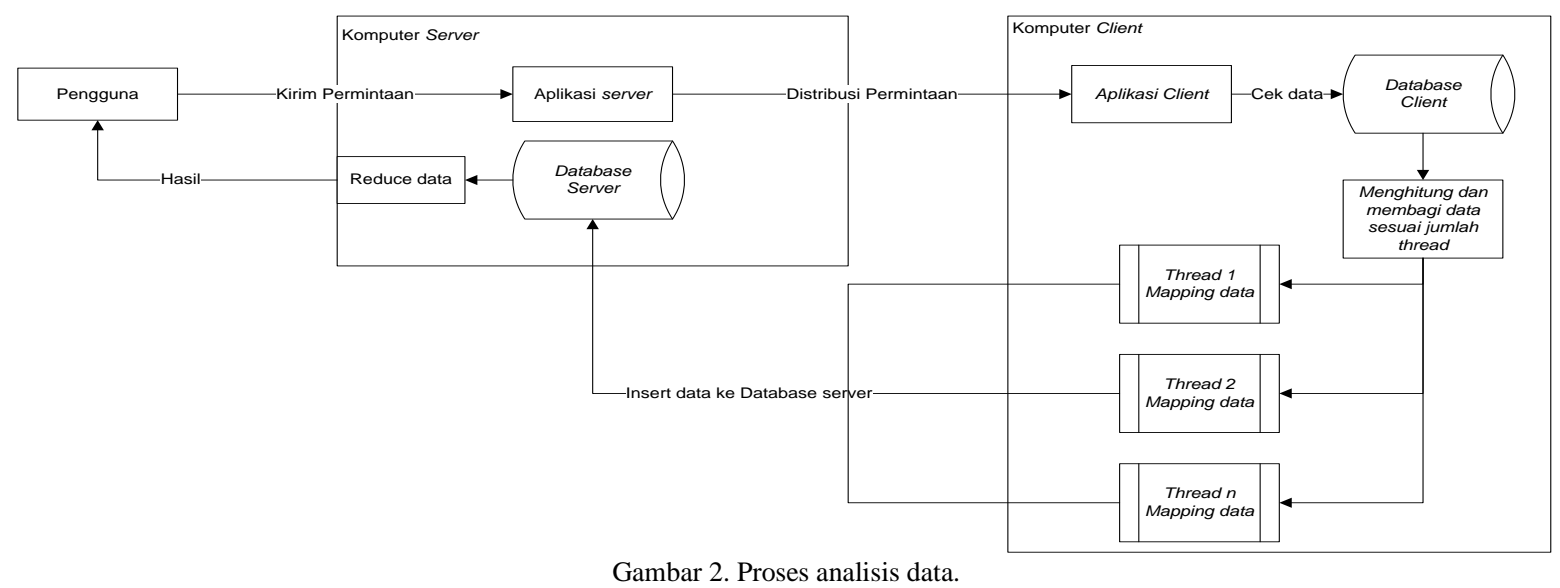

Tahapan analisis data dapat dilihat pada Gambar 2. Proses pengiriman diawali dengan adanya permintaan data yang dibuat oleh pengguna dengan membuat kriteria berupa batasan tanggal dan jumlah thread untuk melakukan proses sinkronisasi, kriteria permintaan data tersebut selanjutnya akan dikirim ke komputer server, komputer server setelah menerima kriteria permintaan data akan mendistribusikan kriteria permintaan data tersebut ke semua komputer client yang terdapat dalam satu jaringan. Komputer client yang sudah menerima kriteria data akan melakukan pengumpulan data dan membagi data sesuai dengan jumlah thread dan melakukan proses sinkronisasi data ke komputer server.

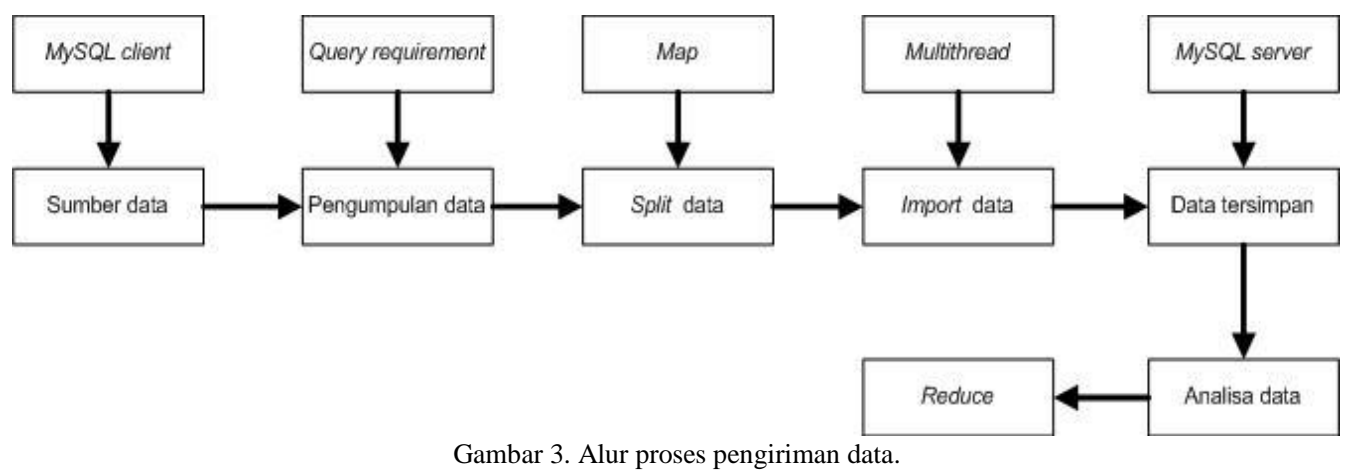

III. HASIL

Hasil pelatihan digunakan untuk mengetahui perbedaan kecepatan sinkronisasi data yang dilakukan dengan secara konvensional dengan single proses yang dibandingkan dengan model pemrograman MapReduce. Dengan demikian akan diketahui kecepatan waktu yang diperoleh dari masing-masing program yang selanjutnya dilakukan 
perbandingan untuk mengetahui selisih waktu dari masing-masing program. Selain pengecekan waktu pemrosesan data juga dicobakan masalah-masalah yang terjadi selama pembuatan sistem seperti pengecekan koneksi, pengecekan port dan pembatasan pengguna (user) yang melakukan transaksi.

Proses pengujian dimulai dengan melakukan pengujian untuk mengetahui waktu yang digunakan untuk membuat thread, melakukan pemrosesan data sebanyak 1000, 10.000, 100.000 dan 1.000.000 data yang akan dilakukan sinkronisasi dengan jumlah pemroses sebanyak 1, 5, 10, 15, 20 dan 25 pada masing-masing jumlah data.

\section{A. PEMBUATAN THREAD}

Thread atau leightweight process (LWP) adalah suatu unit dasar dari CPU Utilization yang berisi program counter, kumpulan register, dan ruang stack. Thread akan berkerja sama dengan thread yang lainnya dalam hal penggunaan bagian kode, bagian data, dan resource dari sistem operasi secara kolektif (task). MapReduce merupakan salah satu model pemrograman yang terdistribusi dan berjalan secara paralel (multithread) yang berfungsi untuk mempercepat pemrosesan data dalam jumlah besar. Hasil dari rata-rata waktu yang digunakan untuk membuat thread sebanyak 25 thread dapat dilihat pada Tabel I. Waktu yang digunakan untuk membuat thread dipengaruhi oleh banyaknya data, jumlah thread yang sudah dibuat dan hardware komputer yang digunakan.

TABEL I

WAKTU PEMBUATAN THREAD (25 THREAD)

\begin{tabular}{crrrr}
\hline \hline \multirow{2}{*}{$\begin{array}{c}\text { Nama } \\
\text { Komputer }\end{array}$} & $\mathbf{1 . 0 0 0}$ & $\mathbf{1 0 . 0 0 0}$ & $\mathbf{1 0 0 . 0 0 0}$ & $\mathbf{1 . 0 0 0 . 0 0 0}$ \\
\cline { 2 - 5 } & 1,52 & 1,36 & 2,80 & 15,96 \\
Komputer 1 & 1,82 & 1,08 & 1,72 & 9,80 \\
Komputer 2 & 1,32 & 1,96 & 1,68 & 20,53 \\
Komputer 3 & 0,68 & 2,24 & 5,32 & 28,24 \\
Komputer 4 & & & & \\
\hline \hline
\end{tabular}

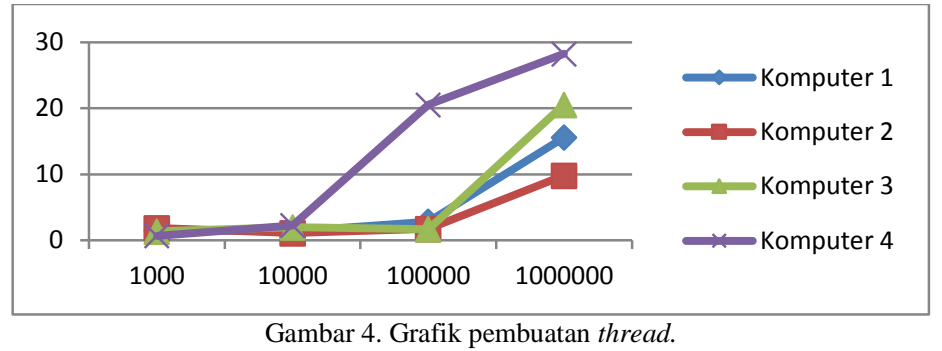

\section{B. PERCOBAAN DENGAN SINGLE PROSES}

Pengujian proses sinkronisasi data yang dilakukan dengan menggunakan proses tunggal pada masing-masing komputer. Pelatihan sinkronisasi data dengan single process (proses tunggal) dilakukan dari 4 buah komputer dengan spesifikasi hardware yang berbeda-beda dan menggunakan jumlah data yang sama yang ada pada masingmasing komputer. Pengujian dilakukan guna untuk mengetahui kecepatan pemrosesan data dengan menggunakan single process.

TABEL II

HASIL PROSES SINKRONISASI DENGAN SINGLE PROCESS

\begin{tabular}{crrrr}
\hline \hline \multirow{2}{*}{$\begin{array}{c}\text { Nama } \\
\text { Komputer }\end{array}$} & $\mathbf{1 . 0 0 0}$ & $\mathbf{1 0 . 0 0 0}$ & $\mathbf{1 0 0 . 0 0 0}$ & $\mathbf{1 . 0 0 0 . 0 0 0}$ \\
\cline { 2 - 5 } Komputer 1 & 34 & 348 & 3.600 & 36.001 \\
Komputer 2 & 36 & 365 & 3.694 & 36.940 \\
Komputer 3 & 36 & 365 & 3.693 & 36.928 \\
Komputer 4 & 36 & 364 & 3.693 & 36.932 \\
\hline \hline
\end{tabular}

Pengujian dilakukan pada semua komputer dengan spesifikasi hardware yang berbeda. Hasil pengujian proses sinkronisasi data yang dilakukan pada semua komputer dengan menggunakan proses tunggal (single process) dengan jumlah data yang sedikit (1.000 data) menunjukan bahwa waktu yang digunakan untuk melakukan proses sinkronisasi data tidak akan lama berkisar antara 34 hingga 36 detik, tetapi ketika dilakukan dengan data yang banyak semisal 1.000.000 data, maka proses sinkronisasi data memerlukan waktu yang lama berkisar antara 36.001 hingga 36.940 detik atau 10 jam 1 detik hingga 10 jam 15 menit 40 detik seperti ditunjukan pada Tabel II. Dari waktu yang diperlukan untuk melakukan sinkronisasi data dengan jumlah data 1.000 .000 hingga 10 jam maka diperlukan sebuah program yang diperlukan untuk melakukan pemrosesan data dengan waktu yang relative lebih singkat. 


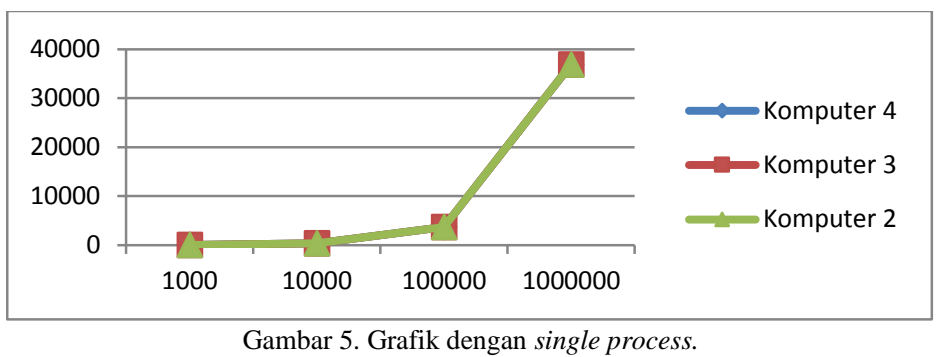

\section{PENGUJIAN DENGAN MODEL PEMROGRAMAN MAPREDUCE \\ 1) MAPPING DATA}

Pada pengujian kedua dengan menggunakan model pemrograman MapReduce yang dipadukan dengan Message Passing dan Static Task Assignment mampu menurunkan waktu pemrosesan data $60 \%$ hingga $70 \%$. Proses diawali dengan adanya pembagian data sesuai dengan jumlah thread yang akan melakukan proses sinkronisasi data, selanjutnya dilakukan proses mapping data sesuai dengan hasil pembagian data. Proses mapping dilakukan bersamaan dengan proses pembuatan thread, masing-masing thread akan memperoleh data yang sama. Contoh dari pembagian data dapat dilihat pada Gambar 6.

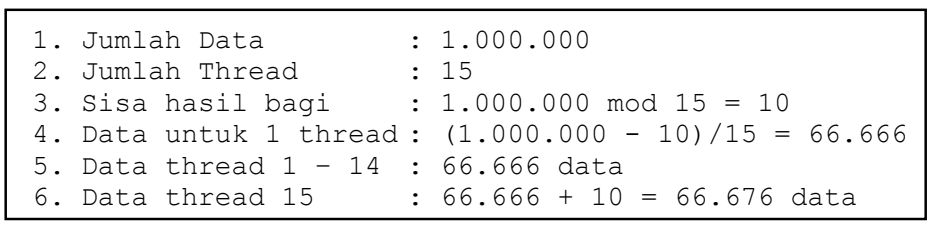

Gambar 6. Contoh pembagian data.

TABEL III

RATA-RATA WAKTU MAPPING DATA (DALAM DETIK)

\begin{tabular}{crrrrrrr}
\hline \multirow{2}{*}{ Nama } & \multirow{2}{*}{ Data } & \multicolumn{7}{c}{ Jumlah Thread } \\
\cline { 3 - 8 } Komputer 1 & 1.000 & 1,52 & 0,85 & 1,00 & 0,60 & 0,0 & 1 \\
Komputer 2 & 1.000 & 1,32 & 0,70 & 0,73 & 1,20 & 1,0 & 1 \\
Komputer 3 & 1.000 & 1,28 & 0,60 & 0,67 & 1,20 & 1,0 & 1 \\
Komputer 4 & 1.000 & 0,68 & 1,15 & 1,00 & 0,90 & 0,4 & 0 \\
Komputer 1 & 10.000 & 1,36 & 1,50 & 0,93 & 0,70 & 1,0 & 0 \\
Komputer 2 & 10.000 & 1,08 & 1,25 & 1,07 & 0,90 & 0,6 & 1 \\
Komputer 3 & 10.000 & 1,96 & 1,20 & 1,00 & 0,80 & 0,6 & 1 \\
Komputer 4 & 10.000 & 2,24 & 1,60 & 0,53 & 1,00 & 1,0 & 0 \\
Komputer 1 & 100.000 & 2,80 & 1,20 & 1,27 & 0,80 & 1,0 & 1 \\
Komputer 2 & 100.000 & 1,72 & 2,15 & 0,87 & 0,70 & 1,0 & 1 \\
Komputer 3 & 100.000 & $1, .68$ & 10,00 & 1,20 & 1,00 & 0,8 & 1 \\
Komputer 4 & 100.000 & 5,32 & 3,20 & 4,33 & 3,00 & 2,0 & 3 \\
Komputer 1 & 1.000 .000 & 15,96 & 15,00 & 11,27 & 8,00 & 5,0 & 2 \\
Komputer 2 & 1.000 .000 & 9,80 & 8,50 & 8,13 & 6,10 & 4,0 & 2 \\
Komputer 3 & 1.000 .000 & 10,52 & 8,70 & 8,20 & 6,20 & 4,6 & 2 \\
Komputer 4 & 1.000 .000 & 28,24 & 25,60 & 20,33 & 17,60 & 11,4 & 10 \\
\hline \hline
\end{tabular}

\section{PEMBAHASAN}

Hasil rata-rata waktu pengujian yang diperlukan untuk melakukan mapping data dan pembuatan thread dengan model pemrograman MapReduce dapat dilihat pada Tabel III dimana dalam tabel tersebut menunjukan hasil pengujian pembuatan thread atau mapping data yang dilakukan pada masing-masing komputer dengan jumlah data yang berbeda dan jumlah thread yang berbeda. Semakin banyak jumlah data yang akan diproses dan jumlah thread yang dibuat semakin banyak maka waktu yang diperlukan untuk melakukan mapping data akan semakin lama demikian pula semakin sedikit thread yang dibuat akan memerlukan waktu yang sedikit pula.

\section{2) REDUCE DATA}

Proses reduce data digunakan untuk menggabungkan data dan menghilangkan data jika terjadi kesamaan data atau duplikasi data hasil dari proses mapping. Proses reduce dilakukan oleh masing-masing komputer setelah proses mapping dan pembuatan thread sudah selesai dibuat. Semua thread yang sudah berhasil dibuat akan melakukan proses reduce data dengan melakukan duplikasi data dari database client ke database server. 


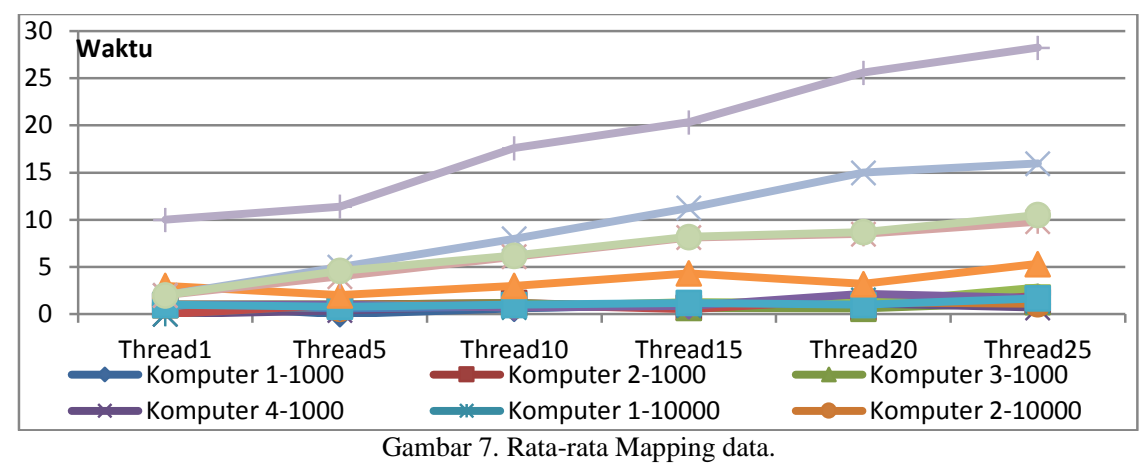

Pada Tabel IV menunjukan hasil sinkronisasi data yang dilakukan dengan model pemrograman MapReduce menunjukan adanya perubahan waktu yang cukup signifikan ketika menggunakan proses tunggal untuk data sebanyak 1.000 menggunakan waktu selama 68 detik, ketika menggunakan model pemrograman MapReduce dengan menggunakan 5 pemroses rata-rata waktu yang diperlukan menurun sekitar 6,8\%, ketika menggunakan 25 pemroses turun hingga hampir $90 \%$, sedangkan menggunakan 20 pemroses turuh hingga $95 \%$ perbedaan waktu antara 20 pemroses dan 25 pemroses disebabkan karena banyak sedikitnya thread yang dibuat untuk melakukan pemrosesan, semakin banyak thread yang dibuat memerlukan waktu yang lebih lama jika dibandingkan dengan thread yang lebih sedikit.

TABEL IV

RATA-RATA WAKTU REDUCE DATA (DALAM DETIK)

\begin{tabular}{|c|c|c|c|c|c|c|c|}
\hline \multirow{2}{*}{ Nama komputer } & \multirow{2}{*}{ Data } & \multicolumn{6}{|c|}{ Thread } \\
\hline & & 25 & 20 & 15 & 10 & 5 & 1 \\
\hline Komputer 1 & 1.000 & 6,00 & 4,00 & 4,60 & 6,00 & 11,00 & 68,00 \\
\hline Komputer 2 & 1.000 & 4,96 & 4,00 & 5,00 & 5,00 & 11,00 & 74,00 \\
\hline Komputer 3 & 1.000 & 3,48 & 4,00 & 5,00 & 5,00 & 11,00 & 74,00 \\
\hline Komputer 4 & 1.000 & 5,32 & 4,00 & 4,07 & 6,00 & 11,00 & 75,00 \\
\hline Komputer 1 & 10.000 & 30,96 & 37,05 & 46,67 & 60,70 & 101,40 & 479,00 \\
\hline Komputer 2 & 10.000 & 31,00 & 38,00 & 48,00 & 65,20 & 108,60 & 520,00 \\
\hline Komputer 3 & 10.000 & 30,68 & 37,90 & 48,33 & 64,80 & 108,20 & 520,00 \\
\hline Komputer 4 & 10.000 & 30,48 & 38,00 & 48,40 & 63,10 & 108,40 & 522,00 \\
\hline Komputer 1 & 100.000 & 351,20 & 297,20 & 342,93 & 407,80 & $1.989,60$ & $4.361,00$ \\
\hline Komputer 2 & 100.000 & 361,24 & 311,65 & 357,93 & 433,50 & $2.055,60$ & $4.461,00$ \\
\hline Komputer 3 & 100.000 & 361,44 & 309,70 & 357,13 & 431,50 & $2.052,60$ & $4.458,00$ \\
\hline Komputer 4 & 100.000 & 356,88 & 307,70 & 353,60 & 433,80 & $2.051,60$ & $4.460,00$ \\
\hline Komputer 1 & 1.000 .000 & $2.754,56$ & $3.244,65$ & $3.449,87$ & $4.731,30$ & $9.464,80$ & $47.360,00$ \\
\hline Komputer 2 & 1.000 .000 & $2.809,80$ & $3.338,00$ & $3.611,07$ & $5.011,50$ & $10.027,60$ & $50.200,00$ \\
\hline Komputer 3 & 1.000 .000 & $2.796,48$ & $3.316,70$ & $3.592,40$ & $4.995,60$ & $9.994,80$ & $49.970,00$ \\
\hline Komputer 4 & 1.000 .000 & $2.765,84$ & $3.694,85$ & $3.552,80$ & $5.613,40$ & 11237.60 & $56.170,00$ \\
\hline
\end{tabular}

Grafik pada Gambar 8 menunjukan rata-rata waktu terbaik terjadi pada komputer dengan spesifikasi hardware komputer tertinggi (Komputer 2) dengan selisih waktu yang tidak terlalu banyak. Semakin banyak thread dibuat semakin lama proses mapping data tetapi semakin cepat proses reduce data.

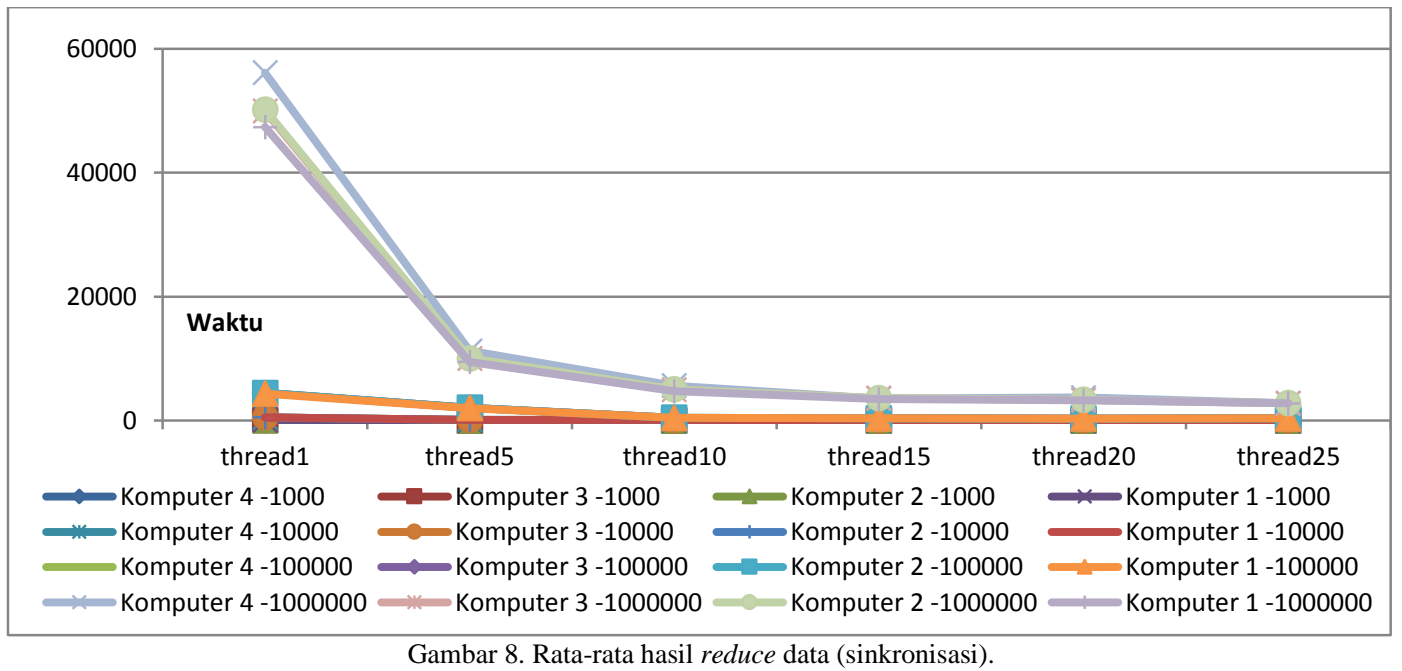


TABEL V

PERBANDINGAN WAKTU REDUCE DATA

\begin{tabular}{|c|c|c|c|c|c|c|c|c|c|c|c|c|c|c|c|c|c|c|c|}
\hline \multirow{2}{*}{$\begin{array}{c}\text { Nama } \\
\text { Komputer }\end{array}$} & \multirow{2}{*}{$\begin{array}{c}\text { Jumlah } \\
\text { Data }\end{array}$} & \multicolumn{3}{|c|}{ Thread 25} & \multicolumn{3}{|c|}{ Thread 20 } & \multicolumn{3}{|c|}{$\begin{array}{l}\text { Thread } 15 \\
\end{array}$} & \multicolumn{3}{|c|}{ Thread 10} & \multicolumn{3}{|c|}{ Thread 5} & \multicolumn{3}{|c|}{ Thread 1} \\
\hline & & avg & $\min$ & $\max$ & avg & $\min$ & $\max$ & avg & $\min$ & $\max$ & avg & $\min$ & $\max$ & avg & $\min$ & $\max$ & avg & $\min$ & $\max$ \\
\hline Komputer 1 & 1.000 & 6.00 & 6 & 6 & 4.00 & 4 & 4 & 4.60 & 4 & 6 & 6.00 & 6 & 6 & 11.00 & 11 & 11 & 68.00 & 68 & 68 \\
\hline Komputer 2 & 1.000 & 4.96 & 4 & 6 & 4.00 & 4 & 4 & 5.00 & 5 & 5 & 5.00 & 5 & 5 & 11.00 & 11 & 11 & 74.00 & 74 & 74 \\
\hline Komputer 3 & 1.000 & 3.48 & 3 & 4 & 4.00 & 4 & 4 & 5.00 & 5 & 5 & 5.00 & 5 & 5 & 11.00 & 11 & 11 & 74.00 & 74 & 74 \\
\hline Komputer 4 & 1.000 & 5.32 & 5 & 6 & 4.00 & 4 & 4 & 4.07 & 4 & 6 & 6.00 & 6 & 6 & 11.00 & 11 & 11 & 75.00 & 75 & 75 \\
\hline Komputer 1 & 10.000 & 30.96 & 30 & 31 & 37.05 & 36 & 38 & 46.67 & 46 & 62 & 60.70 & 59 & 62 & 101.40 & 101 & 102 & 479.00 & 479 & 479 \\
\hline Komputer 2 & 10.000 & 31.00 & 30 & 32 & 38.00 & 38 & 38 & 48.00 & 47 & 66 & 65.20 & 65 & 66 & 108.60 & 108 & 109 & 520.00 & 520 & 520 \\
\hline Komputer 3 & 10.000 & 30.68 & 30 & 31 & 37.90 & 37 & 38 & 48.33 & 47 & 66 & 64.80 & 64 & 66 & 108.20 & 108 & 109 & 520.00 & 520 & 520 \\
\hline Komputer 4 & 10.000 & 30.48 & 30 & 31 & 38.00 & 38 & 38 & 48.40 & 48 & 64 & 63.10 & 62 & 64 & 108.40 & 108 & 109 & 522.00 & 522 & 522 \\
\hline Komputer 1 & 100.000 & 351.20 & 347 & 356 & 297.20 & 296 & 300 & 342.93 & 337 & 410 & 407.80 & 405 & 410 & 1989.60 & 1984 & 1993 & 4361.00 & 4361 & 4361 \\
\hline Komputer 2 & 100.000 & 361.24 & 354 & 365 & 311.65 & 309 & 314 & 357.93 & 355 & 435 & 433.50 & 433 & 435 & 2055.60 & 2054 & 2057 & 4461.00 & 4461 & 4461 \\
\hline Komputer 3 & 100.000 & 361.44 & 357 & 366 & 309.70 & 304 & 312 & 357.13 & 354 & 433 & 431.50 & 430 & 433 & 2052.60 & 2051 & 2055 & 4458.00 & 4458 & 4458 \\
\hline Komputer 4 & 100.000 & 356.88 & 353 & 361 & 307.70 & 304 & 312 & 353.60 & 351 & 436 & 433.80 & 432 & 436 & 2051.60 & 2050 & 2055 & 4460.00 & 4460 & 4460 \\
\hline Komputer 1 & 1.000 .000 & 2754.56 & 2618 & 2776 & 3244.65 & 3113 & 3263 & 3449.87 & 3434 & 4739 & 4731.30 & 4724 & 4739 & 9464.80 & 9448 & 9478 & 47360.00 & 47360 & 47360 \\
\hline Komputer 3 & 1.000 .000 & 2796.48 & 2684 & 2813 & 3316.70 & 3183 & 3348 & 3592.40 & 3580 & 5000 & 4995.60 & 4991 & 5000 & 9994.80 & 9990 & 10000 & 49970.00 & 49970 & 49970 \\
\hline Komputer 4 & 1.000 .000 & 2765.84 & 2652 & 2782 & 3694.85 & 3580 & 3717 & 3552.80 & 3546 & 5620 & 5613.40 & 5604 & 5620 & 11237.60 & 11234 & 11240 & 56170.00 & 56170 & 56170 \\
\hline
\end{tabular}

\section{SIMPULAN DAN SARAN}

Kesimpulan yang dapat diambil setelah dilakukan penelitan dan percobaan adalah sebagai berikut:

1. Penggunaan model pemrograman MapReduce dapat mempercepat waktu untuk melakukan sinkronisasi datadengan cara duplikasi data (parsial sinkronisasi) dari database client ke database server.

2. Proses sinkronisasi data menggunakan 4 node komputer bila dibandingkan dengan menggunakan 1 node komputer. Hasil terbaik ditunjukan dengan memberikan 25 thread untuk melakukan sinkronisasi.

3. Semakin banyak thread yang dibuat dan data yang semakin besar mengkibatkan lamanya waktu yang digunakan untuk melakukan proses mapping data.

4. Berdasarkan pengujian perbedaan antara jumlah waktu pemrosesan dengan menggunakan thread sebanyak 15 dan thread sebanyak 25 perbedaan waktu pemrosesan tidak signifikan.

5. Pengujian model pemrograman MapReduce dengan menggunakan bahasa pemrograman Delphi 2010. Proses pengujian dengan menggunakan data sebanyak 1.000, 10.000, 100.000 dan 1.000 .000 dan thread yang digunakan sebanyak 5, 10, 15, 20 dan 25 thread.

Saran yang diberikan untuk penelitian selanjutnya adalah sebagai berikut:

1. Model pemrograman MapReduce diujicobakan pada bahasa pemrograman diluar bahasa pemrogrman java dan PHP dengan spesifikasi komputer yang sama maupun spesifikasi yang berbeda.

2. Pengunaan data dan jumlah pemrosesan yang lebih banyak lagi untuk mengetahui kendala-kendala yang timbul ketika model pemrograman MapReduce ketika diterapkan pada bahasa pemrograman diluar Java dan PHP.

3. Diujikan pada jumlah komputer yang lebih banyak dengan komputasi awan.

\section{REFERENSI}

[1] Wilkinson, B., dan Allen, M., 2005, (Pararrel Programming Techniques and applications Using Networked Workstations and Computers Second Edition, (diterjemahkan oleh Hidayat, s., Santosa, Y. B. Hery, A. P. dan Himamunanto, R 2010) Penerbit Andi Yogyakarta.

[2] Iqbal M. S., 2012, Implementation MapReduce On Very Large Database System, http://library.gunadarma.ac.id

[3] Khairul, F. A.,dan Suadi, W., 2014, Komputasi Pembobotan Dokumen Berbahasa IndonesiaMenggunakan MapReduce. Fakultas Teknologi Informasi Institut Teknologi Sepuluh Nopember

[4] Kurniawan, E. K., 2010, Penerapan Model Pemrograman MapReduce Pada Sistem Pencarian Milis Linux Di Indonesia, Jurusan Teknik Informatika, Fakultas Teknik dan Ilmu Komputer, Universitas Komputer Indonesia. 